\title{
Drive and habit components of running activity in the rat following food deprivation'
}

\author{
ROY E. CONNALLY, ${ }^{2}$ UNIVERSITY OF COLORADO, Boulder, \\ Colorado
}

This experiment investigated the effects of drive, learning and the interaction of drive and learning on running wheel activity by rats. Employing a design used earlier by Finger \& Reid (1956), in which immediate feeding, following $1 \mathrm{~h}$ in the activity wheel, served as a reinforcement, it was found that increased running was not related to either the number of previous trials or total running trials. Instead, a positive relationship was observed between running and body-weight deficit, and, since body-weight deficit was the operational index of drive, the drive hypothesis was accepted.

One of the most extensively studied aspects of the laboratory rat's behavior has been the relation of general locomotor activity to conditions of food deprivation. It has usually been found that the deprived animal is more active than the animal satiated on food. This relation has been studied in a number of different experimental situations, utilizing several different measures of activity and a variety of food deprivation schedules (Cofer \& Appley, 1964).

In view of the number of studies which have investigated this phenomenon it seems paradoxical that there remains any disagreement as to the relative importance of the major postulated determinants of the correlation between food deprivation and locomotor activity. The most striking discrepancy among the interpretations of this phenomenon offered by various theorists is that some interpret it as representing predominantly associative (i.e., habit) factors, while others attribute it to motivational (i.e., drive) components. This controversy provides the question for this experiment.

The increase in activity following food deprivation has been attributed to drive by some researchers (Duda \& Bolles, 1963; Moskowitz, 1959) and to habit by others (Finger \& Reid, 1956; Finger, Reid, \& Weasner, 1957; Hall, 1958). In the Finger \& Reid (1956) study it was found that immediate feeding, as opposed to delayed feeding, following $1 \mathrm{~h}$ in the activity wheel, served as a reinforcement of the running activity. This being the case, each running session, followed by immediate feeding, can be viewed as a reinforced learning trial. On the other hand, Moskowitz (1959) found that activity increased as a function of body-weight deficit without any provision for reinforcement. Thus for the present study, $l \mathrm{~h}$ in the activity wheel followed by immediate feeding was defined as a reinforced learning trial while body-weight deficit served as the operational index of drive.

The present investigation was designed to examine the independent effects of habit and drive, plus their possible interaction, upon the increase in activity following food deprivation. Data conforming to the function of Fig. 1A, 1B or 1C would support respectively the learning hypothesis, the drive hypothesis or the hypothesis of learning and drive interaction.

Subjects. Forty-eight male Sprague-Dawley rats, 78 days of age on the first experimental day, were assigned to six groups $(N=8)$, matched for weight on the day before the first experimental day.

Apparatus. Sixteen Wahmann activity wheels were enclosed in separate sound-controlled compartments, $21 \times 19 \times 22$ in. Each compartment had an exhaust blower mounted in the back wall and a $7.5 \mathrm{~W}$ light mounted on the ceiling. Wheels were calibrated via the method described by Lacey (1944) and the torque coefficients were periodically checked and recomputed, where necessary, throughout the experiment.

Procedure. Groups IA, IB, IC, ID, and IE were the experimental groups. These groups were maintained on a 23 -h cyclic fooddeprivation schedule for 21 days. Animals of these groups were given daily 1-h periods in activity wheels as follows: Group IA, Days 1-21; Group IB, Days 5-21; Group IC, Days 9-21; Group ID, Days 13-21; and Group ID, Days 17-21.
Group II $(\mathrm{N}=8)$ served as Control Group. These animals were on ad lib feeding throughout the experiment except for the 21 daily $1-h$ periods in the activity wheels. All Ss in all groups were weighed daily just prior to scheduled running periods. Experimental animals were fed for $1 \mathrm{~h}$ immediately following removal from the activity wheels. The Ss were randomly assigned to activity periods and this assignment, consistent throughout the experiment, determined the scheduled hour of feeding for experimental Ss. The Ss were randomly assigned to wheels for each scheduled activity period.

Results. The activity periods of the different groups were initiated in a four-day cycle and thus running scores were computed in series of four trials, one trial per day. This eliminated the need for the data of the $21 \mathrm{st}$ day, and after ascertaining by Fisher's $t$ test that there were no trend changes on this day, these data were excluded from further analysis.

One animal of Group IA performed at extremely high levels and the group mean was much too high to be representative of the running scores of the other seven Ss of this group. Therefore, the group medians were used to test the hypotheses. The mean of the four trials of each four-day series was computed for each $S$ and the medians of these individual scores were established as the group scores for each four-trial series. The Mann-Whitney $U$ test was used for group comparisons.

The effect of food-deprivation upon running activity was established by comparing running scores of Group IA and Group II. Except for Days 1-4, Group IA was significantly more active

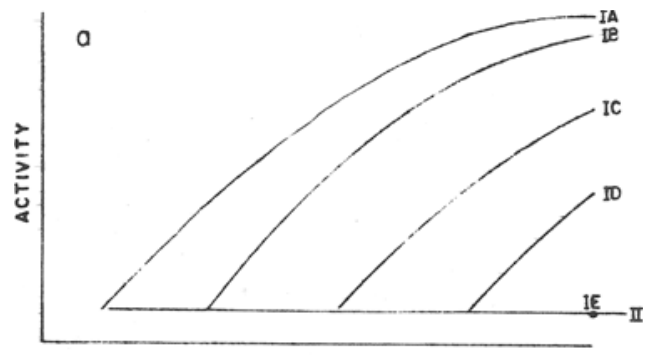

DALYY TRIALS

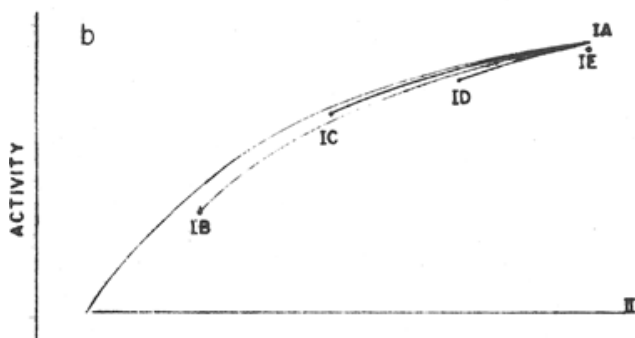

DAILY TRIALS

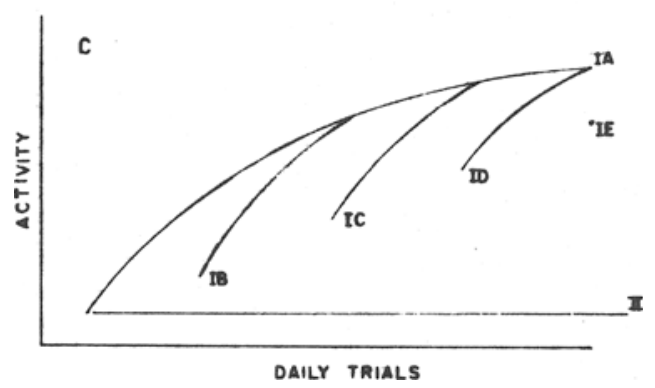

Fig. 1. Functions which would support the learning hypothesis (a) the drive hypothesis (b) or the interaction hypothesis (c). 


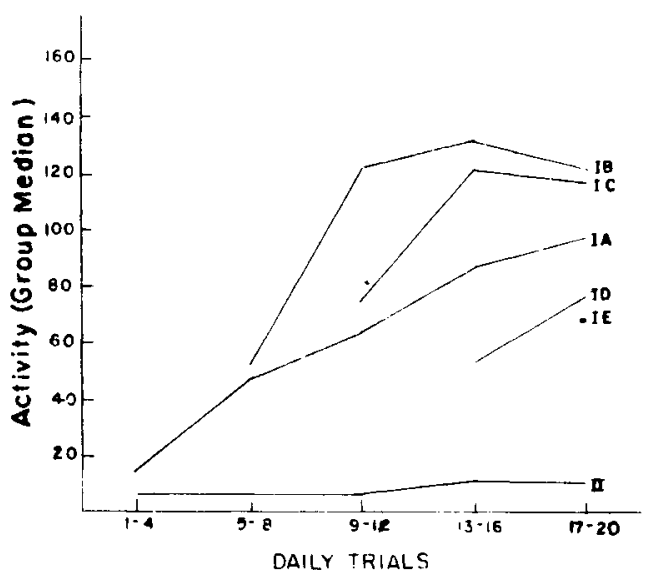

Fig. 2. Median activity all groups.

than Group II. Comparisons were as follows: Days 5-8, $U=13, p=$ .025 ; Days 9-12, $U=7, p=.003$; Days 13-16, and 17-20, $U=1, p$ $=.001$.

Comparisons between running activity of Group IA and the other deprivation groups failed to support the learning hypothesis. Group IA had Trials 5-8 on Days 5-8 while Group IB had Trials 1-4 on Days 5-8, yet Group IA did not perform at a higher level than Group IB for this series of trials. On Days 9-12, Group IA had Trials 9-12 while Group IC had Trials 1-4. Again there was no difference between the two experimental groups. The same results obtained for Group ID on Days 13-16 and Group IE on Days 17-20. The functions of running activity (see Fig. 2) conform more closely to those predicted by the drive hypothesis, Fig. 1b, and thus this hypothesis was accepted and the learning and interaction hypotheses were rejected.

A positive and significant correlation between body-weight deficit (the operational index of drive) and running activity provides further support for the drive hypothesis. The mean running score for each experimental $S$ across each four-day series was correlated with S's mean body-weight deficit, as compared with the ad lib control group, for the same time period. The resulting Pearson Product-moment $\mathrm{r}$ for all experimental Ss was $.52, \mathrm{t}=8.22, \mathrm{df}=118(\mathrm{t}=3.37$ necessary for $\mathrm{p}=.01)$.

In conclusion, it was observed that the functions of running activity by the rat following food-deprivation were more similar to the functions which would be predicted by the drive hypothesis than by a hypothesis of learning or learning and drive interaction. In addition, there was no relationship between running activity and previous running experience. Finally, the correlation between body-weight deficit, the index of drive, and running activity was statistically significant.

\section{REFERENCES}

COFER, C. N., \& APPLEY, M. H. Motivation: theory and research. New York: Wiley, 1964.

DUDA, J. J., \& BOLLES, R. C. Effects of prior deprivation, current deprivation and weight loss in the activity of the hungry rat. J. comp. physiol. Psychol., 1963, 56, 569-571.

FINGER, F. W., REID, L. S. The role of reinforcement on "general activity." Amer. Psychologist, 1956, 11, 426.

FINGER, F. W., REID, L. S., \& WEASNER, M. H. The effect of reinforcement upon activity during cyclic food deprivation. J. comp. physiol. Psychol, 1957, 50, 495-498.

HALL, J. F. The influence of learning in activity wheel behavior. J. genet. Psychol., 1958, 92, 121-125.

LACEY, O. L. A revised procedure for the calibration of the activity wheel. Amer. J. Psychol, 1944, 57, 412-420.

MOSKOWITZ, M. J. Running-wheel activity in the white rat as a function of combined food and water deprivation. J. comp. physiol. Psychol., 1959, $52,621-625$.

\section{NOTES}

1. This research was supported by Public Health Service Predoctoral Fellowship Number 5-F1-MH-28, 837-02 (PS).

2. Now at Temple Buell College, Denver, Colorado. 